\title{
Genetic diversity and association mapping of mineral element concentrations in spinach leaves
}

\author{
Jun Qin ${ }^{1 *}$, Ainong Shi ${ }^{1 *} \mathbb{D}$, Beiquan Mou², Michael A. Grusak ${ }^{3}$, Yuejin Weng ${ }^{1}$, Waltram Ravelombola',
} Gehendra Bhattarai ${ }^{1}$, Lingdi Dong ${ }^{1}$ and Wei Yang ${ }^{1}$

\begin{abstract}
Background: Spinach is a useful source of dietary vitamins and mineral elements. Breeding new spinach cultivars with high nutritional value is one of the main goals in spinach breeding programs worldwide, and identification of single nucleotide polymorphism (SNP) markers for mineral element concentrations is necessary to support spinach molecular breeding. The purpose of this study was to conduct a genome-wide association study (GWAS) and to identify SNP markers associated with mineral elements in the USDA-GRIN spinach germplasm collection.

Results: A total of 14 mineral elements: boron (B), calcium (Ca), cobalt (Co), copper (Cu), iron (Fe), potassium (K), magnesium (Mg), manganese (Mn), molybdenum (Mo), sodium (Na), nickel (Ni), phosphorus (P), sulfur (S), and zinc (Zn) were evaluated in 292 spinach accessions originally collected from 29 countries. Significant genetic variations were found among the tested genotypes as evidenced by the 2 to 42 times difference in mineral concentrations. A total of 2402 SNPs identified from genotyping by sequencing (GBS) approach were used for genetic diversity and GWAS. Six statistical methods were used for association analysis. Forty-five SNP markers were identified to be strongly associated with the concentrations of 13 mineral elements. Only two weakly associated SNP markers were associated with $\mathrm{K}$ concentration. Co-localized SNPs for different elemental concentrations were discovered in this research. Three SNP markers, AYZV02017731_40, AYZV02094133_57, and AYZV02281036_185 were identified to be associated with concentrations of four mineral components, $\mathrm{Co}, \mathrm{Mn}, \mathrm{S}$, and $\mathrm{Zn}$. There is a high validating correlation coefficient with $r>0.7$ among concentrations of the four elements. Thirty-one spinach accessions, which rank in the top three highest concentrations in each of the 14 mineral elements, were identified as potential parents for spinach breeding programs in the future.

Conclusions: The 45 SNP markers strongly associated with the concentrations of the 13 mineral elements: $\mathrm{B}, \mathrm{Ca}$, $\mathrm{Co}, \mathrm{Cu}, \mathrm{Fe}, \mathrm{Mg}, \mathrm{Mn}, \mathrm{Mo}, \mathrm{Na}, \mathrm{Ni}, \mathrm{P}, \mathrm{S}$, and $\mathrm{Zn}$ could be used in breeding programs to improve the nutritional quality of spinach through marker-assisted selection (MAS). The 31 spinach accessions with high concentrations of one to several mineral elements can be used as potential parents for spinach breeding programs.
\end{abstract}

Keywords: Genome-wide association study (GWAS), Genotyping by sequencing (GBS), Mineral elements, Single nucleotide polymorphism (SNP), Spinacia oleracea L., Spinach

\footnotetext{
* Correspondence: junqin@uark.edu; ashi@uark.edu

'Department of Horticulture, University of Arkansas, Fayetteville, AR 72701,

USA

Full list of author information is available at the end of the article
}

(c) The Author(s). 2017 Open Access This article is distributed under the terms of the Creative Commons Attribution 4.0 International License (http://creativecommons.org/licenses/by/4.0/), which permits unrestricted use, distribution, and reproduction in any medium, provided you give appropriate credit to the original author(s) and the source, provide a link to the Creative Commons license, and indicate if changes were made. The Creative Commons Public Domain Dedication waiver (http://creativecommons.org/publicdomain/zero/1.0/) applies to the data made available in this article, unless otherwise stated. 


\section{Background}

Spinach (Spinacia oleracea L., $2 \mathrm{n}=2 \times=12$ ) is an economically important vegetable crop worldwide with an estimated annual value of $\$ 11.8$ billion. The United States (US) is the second largest producer of spinach after China with over 550,000 tons harvested, valued at over $\$ 300$ million annually since 2009 [1, 2]. In addition to its economic importance, spinach is one of the rising vegetable crops in the US in terms of per capita consumption and is considered a healthy vegetable for humans as it is a source of vitamins and mineral nutrients, as well as several health-promoting phytochemicals $[3,4]$.

Minerals originate in the earth and cannot be made by living organisms [5]. Mineral elements are present in different forms in nature and some of these elements are essential for the body to perform different functions [6]. Most of them mediate vital biochemical reactions by acting as a cofactor or catalyst for many enzymes. They also act as centers of building stabilizing structures such as enzymes and proteins. The five major minerals in the human body are calcium $(\mathrm{Ca})$, phosphorus $(\mathrm{P})$, potassium $(\mathrm{K})$, sodium $(\mathrm{Na})$, and magnesium $(\mathrm{Mg})[6,7]$. All of the remaining elements in a human body are called "trace elements". The trace elements that have a specific biochemical function in the human body are iron (Fe), cobalt $(\mathrm{Co})$, copper $(\mathrm{Cu})$, zinc $(\mathrm{Zn})$, manganese $(\mathrm{Mg})$, molybdenum (Mo), iodine (I), and selenium (Se) [8]. Spinach is a dietary source of $\mathrm{Ca}, \mathrm{Cu}, \mathrm{Fe}, \mathrm{K}, \mathrm{Mg}, \mathrm{Mn}, \mathrm{P}$, $\mathrm{Zn}$, folate, vitamins and dietary fiber [9]. Therefore, breeding new spinach varieties with high nutritional components including the mineral elements is one of the main goals in spinach breeding programs worldwide.

Molecular plant breeding has been the foundation for twenty-first-century crop improvement [10]. Markerassisted selection (MAS) has been successfully used to incorporate specific genes/alleles in plant breeding [11-13]. Single nucleotide polymorphism (SNP) with its high abundance, cost efficiency, and highthroughput scoring, has become a powerful tool in genome mapping, association studies, diversity analysis, and tagging of important genes in plant genomics [14-17]. Therefore, identification of SNP markers for mineral elements will be useful in spinach MAS breeding programs.

Genotyping by sequencing (GBS) is one of the nextgeneration sequencing platforms that utilizes a simple highly-multiplexed system for constructing reduced representation libraries which reduces sample handling, requires fewer PCR and purification steps, no size fractionation and uses inexpensive barcoding [18, 19]. As a cost-effective tool for MAS, GBS has been used to facilitate genome-wide association studies (GWAS), genetic linkage analysis, molecular marker discovery, and studies of genomic diversity or selection [18, 20, 21]. As the GBS method has no requirement for a priori knowledge of the species genomes, it has been shown to be robust across a range of species and SNP discovery and genotyping are completed together $[22,23]$. The spinach genome assembly (PacBio Assembly) (980 Mbp) has been reported on January 14, 2014 [24, 25], but it has not been publically available yet. The spinach genome Spinach-1.0.1 is available to the public at http:// www.ncbi.nlm.nih.gov/Traces/wgs/?val=AYZV02 and also at "The Beta vulgaris Resource" website with the page at http://bvseq.molgen.mpg.de/Genome/Download/ Spinach/, representing approximately half of the spinach genome [26, 27]. We used the AYZV02 as the reference of spinach genome sequences for short reads assembly and SNP discovery in each spinach sample in this study.

To date, several association studies for different phenotypic traits of spinach have been reported, such as oxalate concentration [28], leafminer (Liriomyza spp.) resistance [29], Verticillium wilt resistance [30], Stemphylium leaf spot resistance [31], and leaf traits [32]. However, no genetic studies have been conducted to evaluate the genetic diversity of mineral elements and no research has been reported regarding mineral elements using association mapping in spinach natural populations to date. Therefore, the objectives of this study were to perform genetic diversity analysis and GWAS for spinach mineral elements in the USDA spinach germplasm collection, and to identify SNP markers associated with the 14 mineral elements: $\mathrm{B}, \mathrm{Ca}, \mathrm{Co}, \mathrm{Cu}$, $\mathrm{Fe}, \mathrm{K}, \mathrm{Mg}, \mathrm{Mn}, \mathrm{Mo}, \mathrm{Na}, \mathrm{Ni}, \mathrm{P}, \mathrm{S}$, and $\mathrm{Zn}$. The results will provide information on how to use spinach germplasm accessions with high mineral concentrations and new molecular markers for spinach breeding programs.

\section{Results}

Phenotypic variation in the mineral concentrations in spinach USDA-GRIN germplasm

The 14 mineral elements in spinach were analyzed for their mean (average) concentration, range, standard deviation (stdev), and coefficient of variation (CV) for each mineral element (Table 1). Potassium had the highest concentration with greater than $79,500 \mathrm{ppm}$; $\mathrm{Mg}$ the second with 8697 ppm; P, Ca, and S were greater than 4200 ppm; Na and Zn greater than 100 ppm; Mn, Fe, and $\mathrm{B}$ greater than $10 \mathrm{ppm}$; and $\mathrm{Cu}, \mathrm{Mo}, \mathrm{Ni}$, and $\mathrm{Co}$ were less than $7 \mathrm{ppm}$, with $\mathrm{Ni}$ and $\mathrm{Co}$ with less than $1 \mathrm{ppm}$.

All elements showed broad concentration ranges across the germplasm accessions. K, P, Fe, Mg, B, Ca, S, and $\mathrm{Cu}$ had about two to five times difference (Maximum/Minimum); $\mathrm{Na}, \mathrm{Co}, \mathrm{Zn}$, and Mn showed approximately eight to fourteen times difference; while Ni (18 times) and Mo (42 times) exhibited the largest differences (Table 1). The standard deviation and stdev error 
Table 1 The average, range, standard deviation, and coefficient of variation of the 14 mineral compounds in spinach

\begin{tabular}{|c|c|c|c|c|c|c|c|c|}
\hline Mineral compound & No. sample & Average (ppm) & Minimum (ppm) & Maximum (ppm) & Range (ppm) & Standard deviation & Stdev error & $C V(\%)$ \\
\hline $\mathrm{K}$ & 275 & $79,576.06$ & $47,170.00$ & $108,935.36$ & $61,765.37$ & $11,903.06$ & 43.28 & 14.96 \\
\hline Mg & 292 & 8697.34 & 4921.23 & $14,293.27$ & 9372.04 & 1443.39 & 4.94 & 16.60 \\
\hline P & 292 & 6748.91 & 4004.33 & $10,210.77$ & 6206.44 & 952.55 & 3.26 & 14.11 \\
\hline $\mathrm{Ca}$ & 292 & 6400.55 & 3043.91 & $11,544.80$ & 8500.89 & 1511.40 & 5.18 & 23.61 \\
\hline S & 292 & 4281.57 & 1899.60 & 7462.84 & 5563.23 & 782.93 & 2.68 & 18.29 \\
\hline $\mathrm{Na}$ & 292 & 615.76 & 186.94 & 1484.01 & 1297.07 & 214.52 & 0.73 & 34.84 \\
\hline Zn & 292 & 102.50 & 31.43 & 386.82 & 355.38 & 78.97 & 0.27 & 77.04 \\
\hline $\mathrm{Mn}$ & 292 & 83.20 & 29.78 & 415.76 & 385.97 & 79.00 & 0.27 & 94.95 \\
\hline $\mathrm{Fe}$ & 291 & 74.34 & 50.43 & 138.58 & 88.15 & 13.57 & 0.05 & 18.25 \\
\hline B & 269 & 30.47 & 17.07 & 52.36 & 35.29 & 5.93 & 0.02 & 19.47 \\
\hline $\mathrm{Cu}$ & 292 & 6.86 & 2.22 & 10.97 & 8.75 & 1.25 & 0.00 & 18.16 \\
\hline Mo & 292 & 2.36 & 0.20 & 8.62 & 8.42 & 1.29 & 0.00 & 54.96 \\
\hline $\mathrm{Ni}$ & 288 & 0.72 & 0.23 & 4.23 & 4.00 & 0.48 & 0.00 & 66.29 \\
\hline $\mathrm{Co}$ & 238 & 0.15 & 0.05 & 0.46 & 0.42 & 0.08 & 0.00 & 54.01 \\
\hline
\end{tabular}

showed similar trends with their averages. $\mathrm{K}$ had the highest average, and it also had the highest standard deviation and stdev error. The coefficient of variation $(\mathrm{CV})$, also known as relative standard deviation (RSD), is a standardized measure of dispersion of a probability distribution or frequency distribution, where $\mathrm{CV}=$ mean/Stdev $\times 100$. All 14 mineral elements had a large $\mathrm{CV}$ value of greater than $14 \%$. Among them, Co, Mn, $\mathrm{Mo}, \mathrm{Ni}$, and $\mathrm{Zn}$ had greater than $50 \% \mathrm{CV}$ value, indicated that the dispersion in the variable was greater (Table 1), showing there were large variations in these mineral elements across the spinach germplasm accessions. Analyzed from the distributions of mineral concentration values (Fig. 1), Co, $\mathrm{Mn}, \mathrm{Ni}$, and $\mathrm{Zn}$ showed a skewed distribution toward the lower range, and others had near-normal distributions.

The correlation among the 14 mineral elements was analyzed by JMP Genomics 7 . The correlation coefficients among $\mathrm{Co}, \mathrm{Mn}, \mathrm{S}$, and $\mathrm{Zn}$ were greater than 0.7 , indicating strong associations (correlations) among the four mineral elements. In addition, the pairwise correlation coefficients of $\mathrm{Fe}$ and $\mathrm{S}, \mathrm{Fe}$ and $\mathrm{Co}, \mathrm{Fe}$ and $\mathrm{Zn}, \mathrm{Cu}$ and $\mathrm{Mo}, \mathrm{K}$ and $\mathrm{P}$ were greater than 0.4 , indicating significant associations between each pair (Table 2). The two dimension plot of Biplot can be used to visualize the analysis of two-way data. As shown in Fig. 2, the lines that extend from the center and connect to each mineral element trait are considered as index vectors. The angles of the index vectors indicate that correlations existed between the indices (each mineral element trait). The cosine of these angles indicates the genetic correlation. An angle that is less than $90^{\circ}$ indicates a positive correlation, and an angle that is greater than $90^{\circ}$ indicates a negative correlation. If the angle is close to $0^{\circ}$ or $180^{\circ}$, the two indices were highly correlated. The smaller angle between $\mathrm{Co}, \mathrm{Mn}, \mathrm{S}$, and $\mathrm{Zn}$, than other mineral elements, indicates their higher correlation than the other elements (Fig. 2).

\section{Genetic diversity analysis of spinach germplasm}

The population structure of the 292 spinach accessions was initially inferred using STRUCTURE 2.3.4 [33] and the peak of delta $\mathrm{K}$ was observed at $\mathrm{K}=4$, indicating the presence of the four main populations (clusters, Q1-Q4) in the 292 spinach accessions (Fig. 3a). The classification of accessions into populations based on the model-based structure was shown in Fig. 3 and Additional file 1: Table S1. In total, 247 accessions (84.6\%) were assigned to one of the four populations (Q1, Q2, Q3, and Q4). Population 1, 2, 3, and 4 (Q1, Q2, Q3, and Q4) consisted of 33 (11.3\%), 26 (8.9\%), 109 (37.3\%), and 79 (27.0\%) accessions, respectively. The remaining 45 accessions (15.4\%) were categorized as having admixed ancestry, including two, three, and four population admixed among Q1, Q2, Q3, and Q4 (Additional file 1: Table S1).

The genetic diversity was analyzed using the Maximum Likelihood (ML) method by MEGA 6 [34]. Several phylogenetic trees were drawn based on interpretation of results. We defined Q1, Q2, Q3, and Q4 as the clusters and used the same colors as the population structure Q1 (red), Q2 (green), and Q3 (blue), and Q4 (yellow) from the STRUCTURE 2.3.4 (Fig. 3b) to draw the subtrees of the phylogenetic trees in MEGA 6. Two phylogenetic trees were included: (1) without taxon names assigned in order to compare the populations from STRUCTURE (Fig. 3c), and (2) the ring phylogenetic tree (Additional file 2: Figure S1). The phylogenetic trees from MEGA 6 (Fig. 3c and Additional file 2: Figure S1), were well consistent with the 


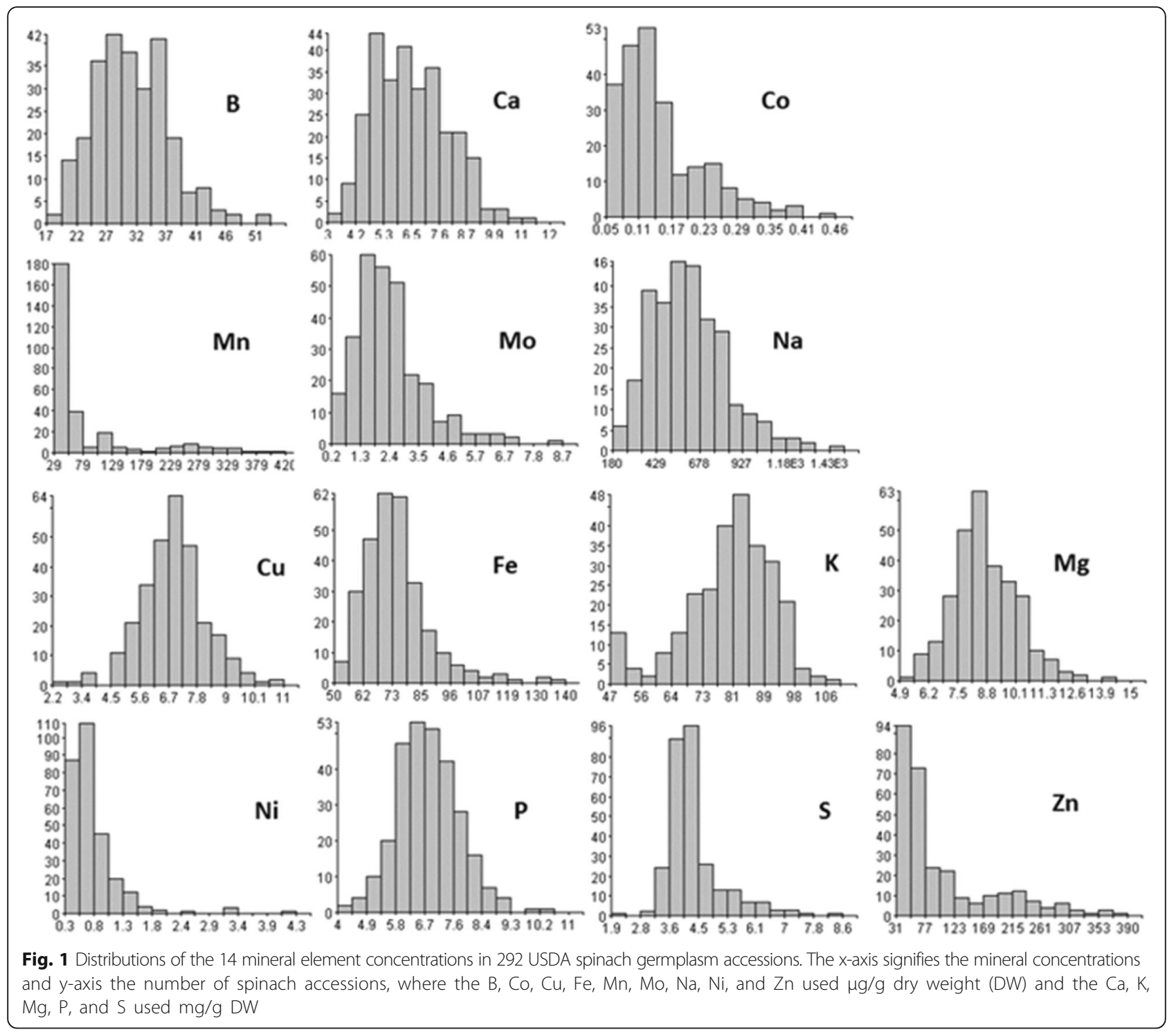

structure populations (Q1-Q4) from STRUCTURE 2.3.4 (Fig. 3a and b), indicating that there were four welldifferentiated genetic populations and admixture in the spinach panel.

\section{Association mapping and SNP marker identification}

Six methods were used for association analysis of the 14 mineral elements among the 292 spinach accessions using 2401 SNPs. The six methods included: (1) SMR_Qgene: single marker regression using the QGene 4.3.10 [35], (2) SMR_tassel: single marker regression without structure and without kinship using TASSEL 5, (3) GLM_tassel: general linear model using TASSEL 5, (4) MLM_tassel: mixed linear model methods using TASSEL 5, (5) cMLM_gapit: compressed mixed linear model methods using GAPIT, and (6) EcMLM_gapit: enriched compressed mixed linear model methods using
GAPIT. The selection standardization in this research is based on LOD values: SMR_QGene, SMR_tassel, and GLM_tassel $>=2.5$, and one of MLM (either MLM_tassel, CMLM_gapit, or EcMLM_gapit) $>=2.5$.

Based on the criteria above, a total of 45 SNPs were identified to be strongly associated with the 13 mineral elements except for $\mathrm{K}$ (Table 3). Among the 45 SNP markers, four were associated with B; one with Ca; seven with $\mathrm{Co}$; two with $\mathrm{Cu}$; six with $\mathrm{Fe}$; four with $\mathrm{Mg}$; five with $\mathrm{Mn}$; one with $\mathrm{Mo}$; five with $\mathrm{Na}$; one with $\mathrm{Ni}$; one with $\mathrm{P}$; seven with $\mathrm{S}$; and five with $\mathrm{Zn}$. In addition, two SNP markers, AYZV02123399_305 and AYZV02147304_372, were detected to be associated with $\mathrm{K}$ having a LOD value $>=2.0$ at SMR_QGene and SMR_tassel, LOD > $=2.5$ at GLM_tassel, and one of MLM models (either MLM_tassel, CMLM_gapit, or EcMLM_gapit). Of these identified markers, four SNPs showed pleiotropic effects: 
Table 2 Correlation coefficient among fourteen mineral components in spinach

\begin{tabular}{lllllllllllllll}
\hline Correlation & $\mathrm{B}$ & $\mathrm{Ca}$ & $\mathrm{Co}$ & $\mathrm{Cu}$ & $\mathrm{Fe}$ & $\mathrm{K}$ & $\mathrm{Mg}$ & $\mathrm{Mn}$ & $\mathrm{Mo}$ & $\mathrm{Na}$ & $\mathrm{Ni}$ & $\mathrm{P}$ & $\mathrm{S}$ & $\mathrm{Zn}$ \\
\hline $\mathrm{B}$ & 1 & 0.09 & 0.12 & 0.22 & 0.11 & 0.09 & -0.15 & 0.07 & 0.23 & 0.03 & 0.07 & -0.01 & 0.15 & 0.23 \\
$\mathrm{Ca}$ & 0.09 & 1 & -0.36 & 0.25 & -0.07 & 0.01 & 0.37 & -0.35 & 0.34 & 0.24 & 0.10 & -0.27 & -0.32 & -0.37 \\
$\mathrm{Co}$ & 0.12 & -0.36 & 1 & 0.14 & 0.44 & -0.35 & -0.21 & 0.72 & -0.31 & -0.04 & 0.02 & -0.14 & 0.70 & 0.74 \\
$\mathrm{Cu}$ & 0.22 & 0.25 & 0.14 & 1 & 0.30 & 0.15 & -0.16 & 0.02 & 0.44 & -0.06 & 0.12 & 0.03 & 0.17 & 0.13 \\
$\mathrm{Fe}$ & 0.11 & -0.07 & 0.44 & 0.30 & 1 & -0.04 & 0.01 & 0.36 & -0.02 & -0.03 & 0.40 & 0.19 & 0.44 & 0.41 \\
$\mathrm{~K}$ & 0.09 & 0.01 & -0.35 & 0.15 & -0.04 & 1 & 0.10 & -0.36 & 0.31 & -0.01 & 0.06 & 0.43 & -0.32 & -0.35 \\
$\mathrm{Mg}$ & -0.15 & 0.37 & -0.21 & -0.16 & 0.01 & 0.10 & 1 & -0.12 & -0.22 & 0.35 & -0.03 & 0.25 & -0.12 & -0.30 \\
$\mathrm{Mn}$ & 0.07 & -0.35 & 0.72 & 0.02 & 0.36 & -0.36 & -0.12 & 1 & -0.35 & -0.02 & -0.03 & -0.09 & 0.76 & 0.81 \\
$\mathrm{Mo}$ & 0.23 & 0.34 & -0.31 & 0.44 & -0.02 & 0.31 & -0.22 & -0.35 & 1 & -0.19 & 0.13 & 0.11 & -0.34 & -0.22 \\
$\mathrm{Na}$ & 0.03 & 0.24 & -0.04 & -0.06 & -0.03 & -0.01 & 0.35 & -0.02 & -0.19 & 1 & 0.00 & -0.06 & 0.05 & -0.16 \\
$\mathrm{Ni}$ & 0.07 & 0.10 & 0.02 & 0.12 & 0.40 & 0.06 & -0.03 & -0.03 & 0.13 & 0.00 & 1 & 0.08 & -0.03 & 0.00 \\
$\mathrm{P}$ & -0.01 & -0.27 & -0.14 & 0.03 & 0.19 & 0.43 & 0.25 & -0.09 & 0.11 & -0.06 & 0.08 & 1 & -0.07 & -0.11 \\
$\mathrm{~S}$ & 0.15 & -0.32 & 0.70 & 0.17 & 0.44 & -0.32 & -0.12 & 0.76 & -0.34 & 0.05 & -0.03 & -0.07 & 1 & 0.72 \\
$\mathrm{Zn}$ & 0.23 & -0.37 & 0.74 & 0.13 & 0.41 & -0.35 & -0.30 & 0.81 & -0.22 & -0.16 & 0.00 & -0.11 & 0.72 & 1 \\
\hline
\end{tabular}

AYZV02017731_35 was associated with both Co and S; AYZV02057049_393 with both Fe and S; AYZV02073631_255 with both Co and S; and AYZV02225779_181 with both Fe and S, indicating each of the four markers can be used to select two mineral components in MAS spinach breeding. Three SNP markers, AYZV02017731_40, AYZV02094133_57, and AYZV02281036_185 were identified to be associated with concentrations of four mineral components, Co, Mn, S, and $\mathrm{Zn}$ based on LOD values: SMR_Qgene (Table 4). Ttest result validated the three SNP markers were significantly associated with the four mineral elements (Table 5),

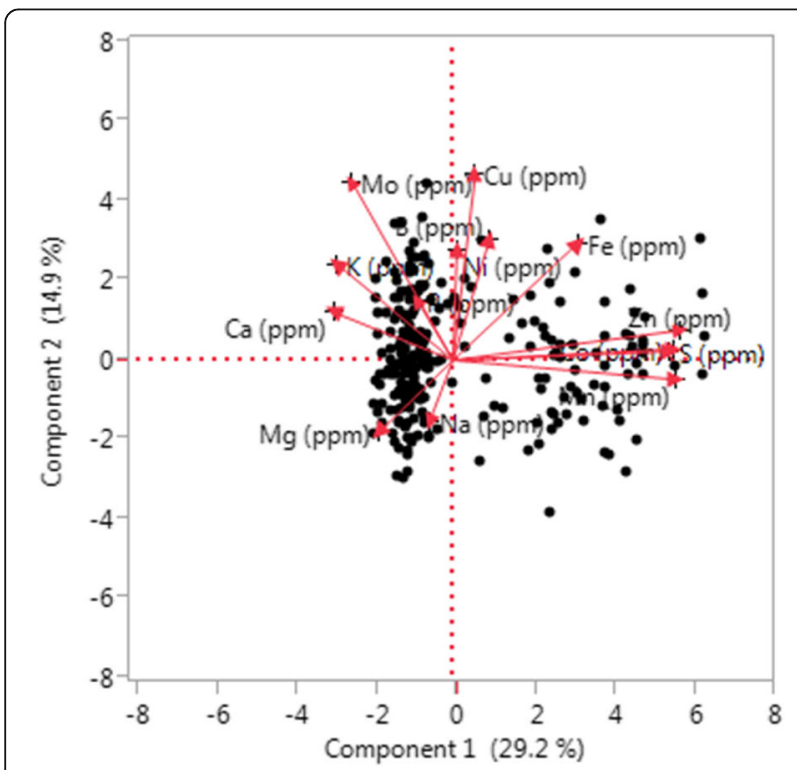

Fig. 2 The two dimension plot of Biplot for 14 mineral element concentrations in 292 spinach germplasm accessions suggesting that it may be possible to select high contents of the four elements, Co, Mn, S, and $\mathrm{Zn}$ at the same time through MAS using these markers in breeding.

R-square (Rsq) of the detected markers using the six different methods were listed in Table 3 with a large range from 1.84\% of the AYZV02144992_13 marker, associated with $\mathrm{Mg}$ in MLM model, to $15.3 \%$ of the AYZV02136507_242, associated with Mn in SMR from Tassel. According to the LOD value, the larger Rsq value of a marker, the stronger association is the marker which makes more contribution to the trait. In all detected SNP markers, AYZV02136507_242 had the greatest Rsq value with 10.6\% Rsq in SMR model from QGene, 15.3\% Rsq in SMR, 13.8\% Rsq in GLM, and 12.9\% Rsq in GLM from Tassel for Mn element, indicating that the AYZV02136507_242 is strongly associated with Mn from this study.

Evaluation and genetic diversity analysis of the top three spinach germplasm accessions for each mineral

We identified the top 3 accessions with the highest concentrations in each of the 14 mineral elements. First, we ordered the 292 spinach accessions based on their mineral concentrations by each individually from the highest to lowest values and gave the order number from 1 to 292 plus the mineral name for each mineral element. For B, as an example, we ordered the B concentration from the highest to lowest and gave each accession with an order ID from B1 to B292 such as NSL6557 had the highest $\mathrm{B}$ value with $52.36 \mathrm{ppm}$ and was given $\mathrm{B} 1$, and NSL6083 the lowest B value with 17.07 ppm given B292 (Additional file 1: Table S1). By combining the $14 \mathrm{~min}-$ eral elements, each accession was given a mineral concentration order ID including the 14 mineral names and 


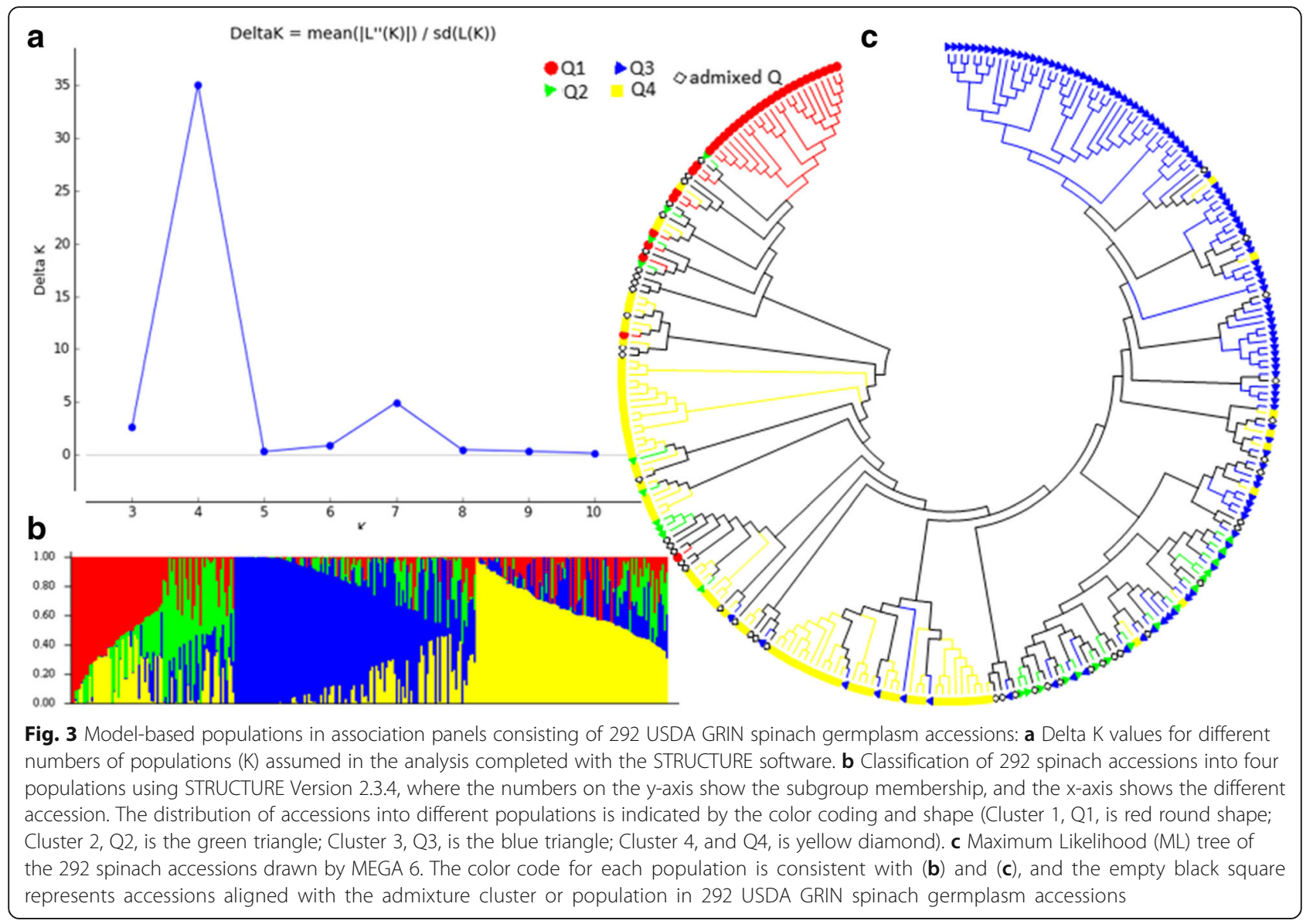

their order numbers. For example, the accession NSL6557 was given the designation B1Ca63Co125Cu41Fe133K284Mg34Mn67Mo36Na161Ni41P19S72Zn100, which means a B rank of 1 , Ca rank of 63, Co rank of $125, \mathrm{Cu}$ rank of 41, Fe rank of 133, etc. for this accession (Additional file 1: Table S2). After ranking all 14 mineral elements, 31 spinach accessions had been chosen because they had at least one mineral element (out of 14) ranked in the top three among the 292 spinach accessions (Additional file 1: Table S2), indicating that the 31 accessions were good mineral element resources for spinach breeding to improve mineral concentrations. Eight out of these 31 spinach accessions had more than two mineral elements ranked in the top 3 highest (PI604777, PI604786, PI175595, PI604782, PI360895, PI339547, PI176372, and PI169671). Three out of the eight accessions had three mineral elements ranked in the top 3 highest. PI604777 was ranked as No. 1 in S, No. 2 in Fe, and No. 3 in Co; PI604786 as No. 2 in Zn, No. 2 in Mn, and No. 3 in Cu; and PI175595 was No. 1 in Ni, No. 3 in P, and No. 3 in K (Additional file 1: Table S2).

The 31 spinach accessions were collected from 10 countries plus one unknown location: ten from Turkey, two from Afghanistan, India, Iran, Japan, Macedonia, and Netherlands, respectively, and one from Mongolia, Belgium, China, Ethiopia, Hungary, Italy, Nepal, and the US, respectively (Additional file 1: Table S2), The genetic diversity analysis was performed for the 31 spinach accessions and the phylogenetic tree was drawn using MEGA 6 (Fig. 4). Based on genetic distances among the 31 genotypes, there were three clusters: Cluster I, consisted of 24 accessions; Cluster II had only two accessions; and Cluster III, included five accessions. The cluster I can be further divided into five sub-clusters (groups): I-1 with seven accessions, I-2, six accessions, I3 , three accessions, I-4, five accessions, and I-5, only two accessions. In addition, PI604788 is an outlier (Fig. 4). The genetic diversity and phylogenetic analysis will provide the information for breeders to choose these spinach accessions as parents in breeding programs.

\section{Discussion}

Application of marker-assisted selection in the genetic improvement of spinach breeding

In this study, we conducted a comprehensive GWAS to identify genetic loci with SNP markers associated with the 14 mineral elements $(\mathrm{B}, \mathrm{Ca}, \mathrm{Co}, \mathrm{Cu}, \mathrm{Fe}, \mathrm{K}, \mathrm{Mg}, \mathrm{Mn}$, 
Table 3 The information of the significant SNP markers associated with 14 mineral compounds among the 292 spinach accessions using six statistical models, SMR_Qgene, SMR_tassel, GLM_tassel, MLM_tassel, CMLM_gapit, and EcMLM_gapit

\begin{tabular}{|c|c|c|c|c|c|c|c|c|c|c|c|c|}
\hline \multirow[t]{3}{*}{ Trait } & \multirow[b]{3}{*}{ Marker } & \multicolumn{6}{|c|}{ LOD value $(-\operatorname{LOG}(p))$} & \multicolumn{4}{|c|}{ R-squre (\%) } & \multirow[t]{3}{*}{ MAF } \\
\hline & & \multirow{2}{*}{$\begin{array}{l}\text { Qgene } \\
\text { SMR }\end{array}$} & \multicolumn{3}{|c|}{ Tassel } & \multicolumn{2}{|l|}{ GAPIT } & \multirow{2}{*}{$\begin{array}{l}\text { Qgene } \\
\text { SMR }\end{array}$} & \multicolumn{3}{|l|}{ Tassel } & \\
\hline & & & SMR & GLM & MLM & CMLM & EcMLM & & SMR & GLM & MLM & \\
\hline B & AYZV02030222_447 & 5.15 & 4.59 & 3.75 & 2.94 & 3.23 & 3.18 & 8.40 & 8.12 & 6.36 & 5.40 & 14.37 \\
\hline B & AYZV02101102_298 & 2.67 & 2.59 & 3.08 & 3.32 & 3.65 & 3.61 & 4.50 & 4.47 & 5.06 & 5.92 & 11.75 \\
\hline B & AYZV02164196_389 & 3.61 & 4.02 & 3.15 & 2.69 & 3.45 & 3.36 & 6.00 & 7.51 & 5.75 & 5.23 & 20.34 \\
\hline B & AYZV02164196_391 & 3.31 & 3.48 & 2.66 & 2.13 & 2.66 & 2.58 & 5.50 & 6.54 & 4.88 & 4.10 & 20.34 \\
\hline $\mathrm{Ca}$ & AYZV02244039_336 & 2.53 & 3.13 & 3.04 & 2.70 & 0.17 & 0.40 & 3.90 & 5.79 & 5.65 & 5.36 & 27.32 \\
\hline $\mathrm{Co}$ & AYZV02017731_35 & 5.64 & 5.75 & 4.16 & 3.77 & 2.99 & 2.38 & 10.30 & 9.80 & 6.26 & 6.15 & 9.92 \\
\hline Co & AYZV02073631_257 & 3.86 & 2.70 & 2.62 & 1.68 & 2.73 & 3.52 & 7.20 & 5.35 & 4.76 & 3.35 & 6.75 \\
\hline Co & AYZV02165009_136 & 3.28 & 3.41 & 3.03 & 2.67 & 2.90 & 2.14 & 6.20 & 5.37 & 4.31 & 4.03 & 9.07 \\
\hline Co & AYZV02217527_245 & 3.74 & 4.15 & 3.17 & 2.15 & 4.34 & 4.53 & 7.00 & 6.58 & 4.44 & 3.15 & 2.74 \\
\hline Co & AYZV02217549_245 & 3.74 & 3.65 & 2.53 & 1.83 & 2.59 & 2.69 & 7.00 & 6.96 & 4.43 & 3.45 & 3.38 \\
\hline Co & AYZV02220844_249 & 3.04 & 3.60 & 3.49 & 3.13 & 3.53 & 2.06 & 5.70 & 6.99 & 6.18 & 6.05 & 10.97 \\
\hline Co & AYZV02221073_190 & 3.41 & 4.18 & 3.19 & 2.96 & 2.28 & 2.10 & 6.40 & 7.15 & 4.81 & 4.80 & 23.63 \\
\hline $\mathrm{Cu}$ & AYZV02147304_383 & 3.01 & 3.27 & 3.62 & 3.01 & 3.27 & 3.30 & 4.60 & 5.22 & 5.62 & 4.98 & 14.09 \\
\hline $\mathrm{Cu}$ & AYZV02277499_79 & 2.75 & 3.45 & 4.67 & 3.66 & 3.21 & 3.33 & 4.20 & 5.76 & 7.49 & 6.43 & 43.30 \\
\hline $\mathrm{Fe}$ & AYZV02057049_393 & 4.68 & 4.61 & 4.90 & 4.41 & 0.10 & 0.12 & 7.10 & 7.33 & 7.54 & 7.35 & 11.90 \\
\hline $\mathrm{Fe}$ & AYZV02201149_106 & 2.85 & 4.08 & 5.48 & 4.74 & 0.44 & 0.10 & 4.40 & 7.43 & 9.36 & 9.37 & 23.45 \\
\hline $\mathrm{Fe}$ & AYZV02201149_51 & 2.65 & 3.01 & 3.59 & 3.21 & 0.45 & 0.05 & 4.10 & 5.58 & 6.27 & 6.27 & 24.14 \\
\hline $\mathrm{Fe}$ & AYZV02207926_4318 & 3.88 & 4.45 & 3.35 & 3.05 & 1.20 & 1.12 & 6.00 & 7.47 & 5.37 & 5.52 & 18.79 \\
\hline $\mathrm{Fe}$ & AYZV02225779_181 & 5.87 & 5.67 & 6.38 & 5.74 & 3.39 & 3.38 & 8.90 & 8.97 & 9.71 & 9.56 & 5.00 \\
\hline $\mathrm{Fe}$ & AYZV02296000_81 & 3.46 & 4.53 & 4.28 & 3.89 & 0.92 & 0.21 & 5.30 & 7.65 & 7.03 & 6.76 & 23.45 \\
\hline $\mathrm{Mg}$ & AYZV02113550_76 & 3.09 & 3.66 & 3.33 & 2.64 & 3.12 & 2.00 & 4.70 & 5.74 & 4.95 & 4.13 & 41.41 \\
\hline $\mathrm{Mg}$ & AYZV02144992_13 & 5.38 & 3.98 & 3.17 & 0.96 & 1.80 & 2.78 & 8.10 & 6.93 & 5.45 & 1.84 & 18.56 \\
\hline $\mathrm{Mg}$ & AYZV02176946_248 & 3.98 & 5.05 & 4.50 & 3.48 & 1.29 & 1.52 & 6.10 & 7.84 & 6.89 & 5.93 & 12.71 \\
\hline $\mathrm{Mg}$ & AYZV02297745_849 & 4.21 & 5.92 & 6.03 & 3.32 & 1.02 & 3.75 & 6.40 & 8.07 & 8.06 & 4.62 & 39.52 \\
\hline $\mathrm{Mn}$ & AYZV02026295_260 & 4.79 & 4.68 & 3.79 & 2.76 & 1.22 & 1.11 & 7.30 & 7.26 & 5.87 & 4.52 & 5.33 \\
\hline $\mathrm{Mn}$ & AYZV02136507_242 & 7.08 & 9.20 & 8.32 & 6.68 & 0.91 & 0.52 & 10.60 & 15.30 & 13.77 & 12.90 & 43.81 \\
\hline $\mathrm{Mn}$ & AYZV02136507_248 & 5.18 & 6.49 & 5.66 & 4.81 & 0.32 & 0.02 & 7.90 & 11.26 & 9.76 & 9.20 & 41.41 \\
\hline $\mathrm{Mn}$ & AYZV02245160_278 & 3.28 & 3.36 & 2.82 & 3.03 & 0.08 & 0.56 & 5.00 & 5.72 & 4.77 & 5.43 & 17.18 \\
\hline $\mathrm{Mn}$ & AYZV02281036_185 & 3.12 & 3.45 & 3.01 & 2.88 & 2.97 & 1.95 & 4.80 & 5.69 & 4.95 & 5.14 & 8.59 \\
\hline Mo & AYZV02092600_720 & 3.15 & 3.77 & 4.04 & 3.88 & 3.45 & 3.76 & 4.80 & 4.82 & 5.05 & 5.10 & 4.81 \\
\hline $\mathrm{Na}$ & AYZV02103789_734 & 3.52 & 3.65 & 2.87 & 2.50 & 2.10 & 2.06 & 5.40 & 4.93 & 3.61 & 3.17 & 13.57 \\
\hline $\mathrm{Na}$ & AYZV02156839_631 & 3.08 & 3.11 & 2.86 & 2.68 & 0.02 & 0.07 & 4.70 & 5.30 & 4.77 & 4.93 & 23.54 \\
\hline $\mathrm{Na}$ & AYZV02178194_42 & 3.38 & 4.11 & 2.70 & 2.08 & 2.57 & 1.84 & 5.20 & 6.23 & 3.70 & 2.84 & 28.87 \\
\hline $\mathrm{Na}$ & AYZV02209560_3 & 3.77 & 4.59 & 3.42 & 2.84 & 3.16 & 3.31 & 5.80 & 6.29 & 4.40 & 3.72 & 13.40 \\
\hline $\mathrm{Na}$ & AYZV02225745_194 & 3.05 & 3.21 & 2.59 & 2.24 & 1.93 & 2.51 & 4.70 & 4.48 & 3.42 & 2.91 & 18.56 \\
\hline $\mathrm{Ni}$ & AYZV02051025_93 & 3.40 & 6.42 & 5.77 & 4.87 & 0.30 & 0.31 & 5.30 & 10.33 & 9.23 & 8.71 & 28.92 \\
\hline$P$ & AYZV02105368_125 & 2.88 & 3.40 & 3.54 & 2.82 & 2.91 & 2.80 & 4.40 & 5.82 & 6.05 & 5.09 & 11.00 \\
\hline S & AYZV02017731_35 & 3.84 & 4.33 & 3.39 & 2.84 & 2.08 & 1.38 & 5.90 & 5.92 & 4.39 & 3.71 & 10.14 \\
\hline S & AYZV02057049_393 & 3.78 & 3.88 & 4.21 & 3.64 & 0.29 & 0.07 & 5.80 & 6.18 & 6.55 & 6.19 & 11.86 \\
\hline S & AYZV02073631_255 & 3.58 & 2.69 & 2.83 & 2.52 & 3.04 & 2.82 & 5.50 & 4.40 & 4.53 & 4.28 & 6.70 \\
\hline S & AYZV02073631_257 & 3.65 & 2.79 & 2.88 & 2.57 & 3.34 & 3.05 & 5.60 & 4.54 & 4.59 & 4.35 & 6.36 \\
\hline
\end{tabular}


Table 3 The information of the significant SNP markers associated with 14 mineral compounds among the 292 spinach accessions using six statistical models, SMR_Qgene, SMR_tassel, GLM_tassel, MLM_tassel, CMLM_gapit, and EcMLM_gapit (Continued)

\begin{tabular}{|c|c|c|c|c|c|c|c|c|c|c|c|c|}
\hline \multirow[t]{3}{*}{ Trait } & \multirow[b]{3}{*}{ Marker } & \multicolumn{6}{|c|}{ LOD value $(-\mathrm{LOG}(\mathrm{p}))$} & \multicolumn{4}{|c|}{ R-squre (\%) } & \multirow[t]{3}{*}{ MAF } \\
\hline & & \multirow{2}{*}{$\begin{array}{l}\text { Qgene } \\
\text { SMR }\end{array}$} & \multicolumn{3}{|c|}{ Tassel } & \multicolumn{2}{|l|}{ GAPIT } & \multirow{2}{*}{$\begin{array}{l}\text { Qgene } \\
\text { SMR }\end{array}$} & \multicolumn{3}{|c|}{ Tassel } & \\
\hline & & & SMR & GLM & MLM & CMLM & ECMLM & & SMR & GLM & MLM & \\
\hline$S$ & AYZV02094133_57 & 5.36 & 6.48 & 6.15 & 4.96 & 3.06 & 2.46 & 8.10 & 9.70 & 8.95 & 7.87 & 16.32 \\
\hline S & AYZV02225779_181 & 4.28 & 4.12 & 4.45 & 3.87 & 0.01 & 0.03 & 6.50 & 6.57 & 6.92 & 6.37 & 4.98 \\
\hline$S$ & AYZV02248538_132 & 2.75 & 3.60 & 3.49 & 3.74 & 1.22 & 1.08 & 4.20 & 5.93 & 5.61 & 6.35 & 9.28 \\
\hline $\mathrm{Zn}$ & AYZV02066684_19177 & 3.71 & 3.24 & 3.19 & 2.72 & 0.66 & 0.57 & 5.70 & 5.46 & 4.97 & 5.44 & 14.95 \\
\hline $\mathrm{Zn}$ & AYZV02151846_237 & 3.06 & 5.43 & 3.09 & 2.17 & 2.53 & 1.71 & 4.70 & 8.58 & 4.29 & 3.49 & 36.08 \\
\hline $\mathrm{Zn}$ & AYZV02201848_2665 & 5.11 & 5.16 & 4.30 & 3.96 & 2.69 & 2.72 & 7.70 & 8.14 & 6.34 & 6.59 & 11.34 \\
\hline $\mathrm{Zn}$ & AYZV02212287_92 & 2.54 & 3.92 & 4.91 & 3.15 & 1.66 & 1.46 & 3.90 & 6.57 & 7.41 & 5.26 & 17.01 \\
\hline $\mathrm{Zn}$ & AYZV02212288_92 & 3.30 & 4.13 & 5.27 & 3.69 & 2.53 & 2.32 & 5.10 & 7.19 & 8.27 & 6.19 & 19.59 \\
\hline K & AYZV02123399_305 & 2.07 & 2.25 & 2.77 & 2.61 & 2.53 & 2.80 & 3.40 & 4.05 & 4.94 & 4.84 & 25.00 \\
\hline K & AYZV02147304_372 & 2.33 & 2.21 & 2.48 & 2.53 & 2.09 & 1.69 & 3.80 & 3.90 & 4.36 & 4.47 & 18.43 \\
\hline
\end{tabular}

Mo, Na, Ni, P, S, and Zn) in 292 spinach accessions of the USDA collection. A total of 45 SNP markers were identified to be associated with the 13 mineral elements except $\mathrm{K}$, based on six different association mapping models. Similar mineral element association mapping research has been reported in other crops, such as pea [36] and rice [37-40] using RIL or diversity populations. Ma et al. (2017) [36] conducted a comprehensive QTL mapping study and identified genetic loci associated with mineral element concentrations ( $\mathrm{B}, \mathrm{Ca}, \mathrm{Fe}, \mathrm{K}, \mathrm{Mg}, \mathrm{Mn}$, Mo, $\mathrm{P}, \mathrm{S}$ and $\mathrm{Zn}$ ) in pea seeds using a RIL population.

Co-localization of SNPs for different element concentrations has been discovered in this research. AYZV02017731_35 and AYZV02073631_257 were related to Co and S, AYZV02057049_393 was related to both Fe and S, and AYZV02225779_181 was related to Fe and S (Table 3). Co-localization of QTLs for different element concentrations in seeds has previously been reported in rice $[37,38,41]$. Genetically, the phenomenon of co-localization may be caused by pleiotropy of a single gene product being involved in the transport and/or physiological processing of multiple elements. Another possibility is the presence of clustered genes that are tightly associated together and responsible for the accumulation of different elements [42].

Accordingly, the high positive correlations among Co, $\mathrm{S}, \mathrm{Mn}$, and $\mathrm{Zn}$ ranged from 0.70 to 0.81 in this study (Table 2). The positive correlations suggest that high Co,

Table 4 The information of three significant SNP markers associated with four mineral compounds among the 292 spinach accessions using six statistical models, SMR_Qgene, SMR_tassel, GLM_tassel, MLM_tassel, CMLM_gapit, and EcMLM_gapit. Co, $\mathrm{Mn}, \mathrm{S}$, and $\mathrm{Zn}$ based on T-tesing at $P=0.05$

\begin{tabular}{|c|c|c|c|c|c|c|c|c|c|c|c|c|}
\hline \multirow[t]{3}{*}{ Trait } & \multirow[b]{3}{*}{ Marker } & \multicolumn{6}{|c|}{ LOD value (-LOG(p)) } & \multicolumn{4}{|c|}{ R-squre (\%) } & \multirow[t]{3}{*}{ MAF } \\
\hline & & \multirow{2}{*}{$\begin{array}{l}\text { Qgene } \\
\text { SMR }\end{array}$} & \multicolumn{3}{|c|}{ Tassel } & \multicolumn{2}{|l|}{ GAPIT } & \multirow{2}{*}{$\begin{array}{l}\text { Qgene } \\
\text { SMR }\end{array}$} & \multicolumn{3}{|c|}{ Tassel } & \\
\hline & & & SMR & GLM & MLM & CMLM & ECMLM & & SMR & GLM & MLM & \\
\hline Co & AYZV02017730_40 & 3.74 & 3.83 & 2.35 & 1.98 & 2.26 & 1.55 & 7.00 & 6.12 & 3.16 & 2.78 & 7.17 \\
\hline $\mathrm{Mn}$ & AYZV02017730_40 & 2.06 & 2.65 & 2.10 & 1.15 & 0.99 & 0.66 & 3.20 & 3.28 & 2.46 & 1.17 & 6.53 \\
\hline S & AYZV02017730_40 & 3.25 & 3.95 & 3.09 & 2.42 & 2.22 & 1.47 & 5.00 & 5.17 & 3.83 & 3.01 & 6.53 \\
\hline $\mathrm{Zn}$ & AYZV02017730_40 & 3.35 & 3.93 & 2.63 & 2.04 & 1.80 & 1.19 & 5.10 & 5.15 & 2.98 & 2.51 & 6.53 \\
\hline Co & AYZV02094133_57 & 2.07 & 2.53 & 1.46 & 1.27 & 1.08 & 0.65 & 3.90 & 4.18 & 1.93 & 1.78 & 16.67 \\
\hline $\mathrm{Mn}$ & AYZV02094133_57 & 4.04 & 4.50 & 3.49 & 2.16 & 0.33 & 0.63 & 6.20 & 6.56 & 4.88 & 2.98 & 16.32 \\
\hline$S$ & AYZV02094133_57 & 5.36 & 6.48 & 6.15 & 4.96 & 3.06 & 2.46 & 8.10 & 9.70 & 8.95 & 7.87 & 16.32 \\
\hline $\mathrm{Zn}$ & AYZV02094133_57 & 1.62 & 2.30 & 1.99 & 1.13 & 0.49 & 0.17 & 2.50 & 3.04 & 2.35 & 1.28 & 16.32 \\
\hline Co & AYZV02281036_185 & 2.29 & 1.54 & 1.12 & 1.06 & 2.37 & 1.41 & 4.30 & 3.17 & 2.12 & 2.23 & 9.07 \\
\hline$M n$ & AYZV02281036_185 & 3.12 & 3.45 & 3.01 & 2.88 & 2.97 & 1.95 & 4.80 & 5.69 & 4.95 & 5.14 & 8.59 \\
\hline S & AYZV02281036_185 & 2.35 & 2.00 & 1.70 & 1.75 & 1.71 & 1.35 & 3.60 & 3.34 & 2.78 & 3.03 & 8.59 \\
\hline $\mathrm{Zn}$ & AYZV02281036_185 & 2.86 & 2.85 & 2.60 & 2.47 & 3.19 & 2.76 & 4.40 & 4.73 & 3.97 & 4.22 & 8.59 \\
\hline
\end{tabular}


Table 5 Three SNP markers significantly associated with two to four of the four mineral compound, Co, Mn, S, and Zn based on T-tesing at $\mathrm{P}=0.05$

\begin{tabular}{|c|c|c|c|c|c|c|c|c|c|c|c|c|}
\hline \multirow[t]{2}{*}{ SNP } & \multicolumn{3}{|l|}{ Co } & \multicolumn{3}{|l|}{$\mathrm{Mn}$} & \multicolumn{3}{|l|}{$S$} & \multicolumn{3}{|l|}{$\mathrm{Zn}$} \\
\hline & Allele & Significant & LSM & Allele & Significant & LSM & Allele & Significant & LSM & Allele & Significant & LSM \\
\hline AYZV02017730_40 & & & & GG & A & 320.375 & GG & A & 6539.647 & GG & A & 287.886 \\
\hline AYZV02017730_40 & & & & $\mathrm{CC}$ & B & 235.260 & $\mathrm{CC}$ & B & 5550.364 & $\mathrm{CC}$ & B & 189.567 \\
\hline AYZV02094133_57 & & & & $\mathrm{CC}$ & A & 302.734 & $\mathrm{CC}$ & A & 6461.113 & & & \\
\hline AYZV02094133_57 & & & & AA & B & 256.411 & $\mathrm{AA}$ & B & 5835.309 & & & \\
\hline AYZV02281036_185 & AA & A & 0.428 & AA & A & 283.587 & AA & A & 6397.044 & $\mathrm{AA}$ & A & 306.576 \\
\hline AYZV02281036_185 & $\mathrm{CC}$ & B & 0.384 & $\mathrm{CC}$ & B & 219.221 & $\mathrm{CC}$ & B & 5847.326 & $\mathrm{CC}$ & B & 240.304 \\
\hline AYZV02281036_185 & $A C$ & $A B$ & 0.366 & $A C$ & $A B$ & 361.036 & $A C$ & $A B$ & 6037.149 & $A C$ & $A B$ & 215.736 \\
\hline
\end{tabular}

$\mathrm{S}, \mathrm{Mn}$ and $\mathrm{Zn}$ concentrations could be possible in individual spinach accessions. For the four mineral elements (Co, S, Mn and $\mathrm{Zn}$ ), eleven highly significantly associated SNP markers were identified in this study (Table 3).

These markers related to mineral elements have low LOD and small R-squared values because the mineral elements are controlled by multiple genes with minor effects. How to apply these SNP markers in spinach germplasm evaluation and breeding is a challenge for spinach breeders. Next step of research is going to validate these SNP markers using KASP SNP genotyping: 1) To validate the stability of these SNP markers across multiple locations and years; 2) To conduct an additional association mapping study on another natural population panel in order to identify potential overlaps

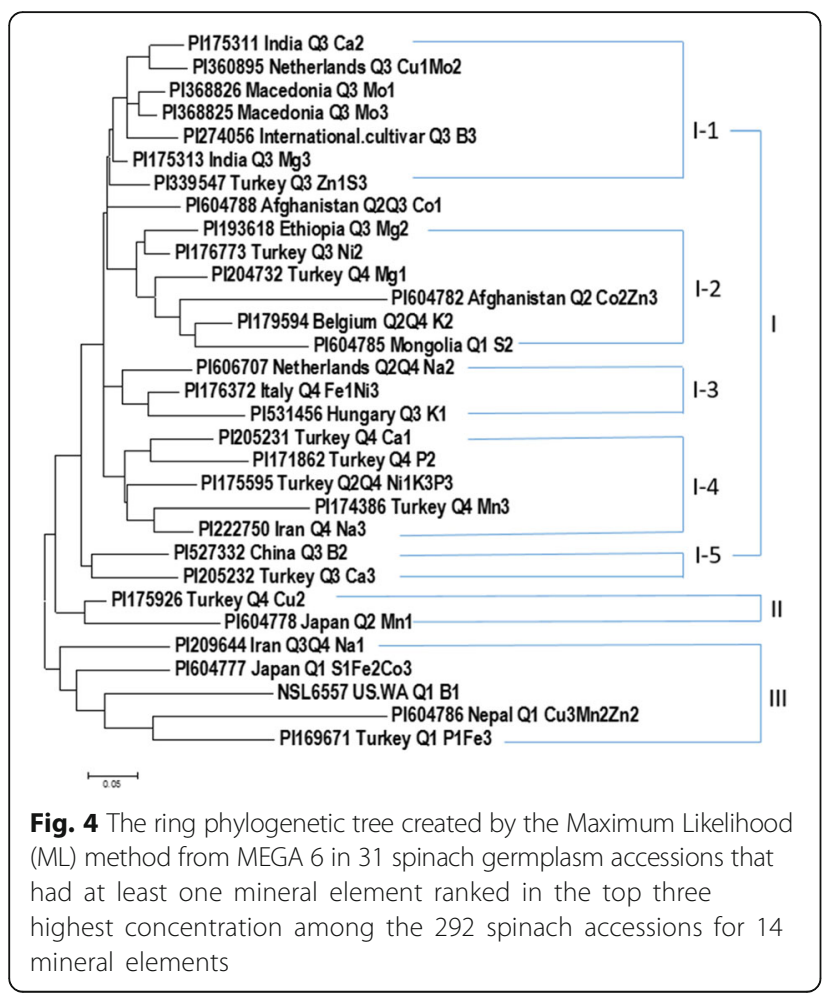

with what we are reporting; 3) To develop bi-parental populations to validate and identify SNP markers linked to mineral elements and try to find SNP markers with major effect; 4) To use genomic selection approach to select the minor effect alleles to improve element compositions in spinach cultivars.

This comprehensive spinach mineral nutrient study provides a foundation of SNP markers to improve mineral content in spinach cultivar development. The future release of a spinach reference genome sequence will enable a complete analysis of these trait loci.

\section{Mineral elements related to nutrition and human healthy food in spinach}

The mineral elements are essential and indispensable for growth and health, having a direct or indirect effect on the metabolism and physiological processes of humans and plants as well. Deficiencies or insufficient intake of minerals may lead to several dysfunctions and diseases in humans [43]. There is a growing interest in the mineral and phytochemical composition of foods and diets, and especially in leafy vegetables. Recent studies with Mexican, Central American, and African green leafy vegetables, including Cnidoscolus aconitifolius, Crotalaria longirostrata, Solanum scabrum, Gynandropsis gyandra, and several leafy Amaranthus species, have highlighted the contributions that these vegetables can provide to one's daily intake of essential nutrients and healthbeneficial compounds $[44,45]$.

Mineral elements in spinach have been reported by other studies employing a large number of techniques [46-51]. On a moisture-free basis, the highest levels of $\mathrm{K}, \mathrm{Ca}, \mathrm{Na}, \mathrm{P}, \mathrm{Mg}, \mathrm{S}, \mathrm{Zn}, \mathrm{Cu}, \mathrm{Co}$, and $\mathrm{B}$ were found in spinach compared to parsley, dill, and mint [52]. In this research, 14 mineral elements were detected in 292 spinach accessions, including macro-elements $(\mathrm{K}, \mathrm{Mg}, \mathrm{P}, \mathrm{Ca}$, and $\mathrm{S}$ ) and micro-elements $(\mathrm{Na}, \mathrm{Zn}, \mathrm{Mn}, \mathrm{B}, \mathrm{Fe}, \mathrm{Cu}, \mathrm{Mo}$, $\mathrm{Co}$, and $\mathrm{Ni})$. These findings provide a new range of spinach mineral values for dieticians and nutrition scientists to consider when calculating nutrient intakes of spinach- 
containing diets, or when developing healthful menu recommendations.

$\mathrm{Na}, \mathrm{K}, \mathrm{Mg}$, and $\mathrm{Ca}$ are the four main and essential electrolytes for humans, $\mathrm{Na}$ is responsible for controlling the total amount of water in the body. It is also important for regulating blood volume and maintaining muscle and nerve function. $\mathrm{Mg}$ is the most abundant intracellular divalent cation. It is an essential cofactor for a multitude of enzymatic reactions that are important for the generation of energy from ATP and for physiologic processes, including neuromuscular function and maintenance of cardiovascular tone [53]. $\mathrm{Ca}$ is the major component of bone and assists in tooth development [54]. $\mathrm{K}$ is an important component of cell and body fluids that helps to control heart rate and blood pressure (http://www.nutrition-and-you.com/spinach.html).

Among the 292 spinach accessions from this research, the highest levels of $\mathrm{Na}, \mathrm{K}, \mathrm{Mg}$, and $\mathrm{Ca}$ were found to have $1484.01 \mathrm{ppm}, 108,935.36 \mathrm{ppm}, 14,293.27 \mathrm{ppm}$, and 10,210.76 ppm in PI209644 from Iraq, PI531456 from Hungary, PI204732 from Turkey, and PI205231 from Turkey, respectively (Additional file 1: Table S1). In addition, the top three spinach germplasm accessions in each mineral element were also listed and provide information on how to use these high mineral accessions in breeding programs. The PI accessions containing beneficial SNPs associated with mineral elements will be highly valuable for the spinach breeders to use for the development of cultivars with high mineral element concentrations through MAS and GS (genomic selection). The significant genetic variations among genotypes as evidenced by the 2 to 42 times difference in mineral concentration (Table 1) suggest that the genetic improvement of mineral traits is feasible in spinach. The co-localization of SNP markers and the positive correlations in concentrations for many mineral elements make it possible to pyramid high concentrations of multiple elements into a single cultivar in a spinach breeding program.

\section{Conclusions}

A total of 14 mineral elements: boron (B), calcium (Ca), cobalt $(\mathrm{Co})$, copper $(\mathrm{Cu})$, iron $(\mathrm{Fe})$, potassium $(\mathrm{K})$, magnesium $(\mathrm{Mg})$, manganese $(\mathrm{Mn})$, molybdenum (Mo), sodium $(\mathrm{Na})$, nickel $(\mathrm{Ni})$, phosphorus $(\mathrm{P})$, sulfur $(\mathrm{S})$, and zinc $(\mathrm{Zn})$ were evaluated in 292 spinach accessions originally collected from 29 countries. The 45 SNP markers strongly associated with the concentrations of the 13 mineral elements: $\mathrm{B}, \mathrm{Ca}, \mathrm{Co}, \mathrm{Cu}, \mathrm{Fe}, \mathrm{Mg}, \mathrm{Mn}, \mathrm{Mo}, \mathrm{Na}$, $\mathrm{Ni}, \mathrm{P}, \mathrm{S}$, and $\mathrm{Zn}$ using six statics methods, including single marker regression using Q-gene (SMR), single marker regression using Tassel (SMR), general linear model using Tassel (GLM), mixed linear model using Tassel (MLM), compressed mixed linear model using
Gapit (cMLM), and enriched compressed mixed linear model using Gapit (EcMLM). Three SNP markers, AYZV02017731_40, AYZV02094133_57, and AYZV02281036_185 were identified to be associated with concentrations of four mineral components, Co, $\mathrm{Mn}, \mathrm{S}$, and $\mathrm{Zn}$. The markers could be used in breeding programs to improve the nutritional quality of spinach through marker-assisted selection (MAS). Thirty-one spinach accessions with high concentrations of one to several mineral elements can be used as potential parents for spinach breeding programs.

\section{Methods \\ Plant materials}

A total of 292 accessions of spinach (S. oleracea) USDAGRIN (US Department of Agriculture, Germplasm Resources Information Network) germplasm originally collected from 29 countries plus 18 unknown locations were used for genetic diversity and association analysis of mineral elements in this study (Additional file 1: Table S1). All seeds were kindly provided by David Brenner at USDAARS (Agricultural Research Service) and Iowa State University at Ames, IA, US.

\section{Leaf mineral concentration evaluation}

Concentrations of 14 mineral components: $\mathrm{B}, \mathrm{Ca}, \mathrm{Co}$, $\mathrm{Cu}, \mathrm{Fe}, \mathrm{K}, \mathrm{Mg}, \mathrm{Mn}, \mathrm{Mo}, \mathrm{Na}, \mathrm{Ni}, \mathrm{P}, \mathrm{S}$, and $\mathrm{Zn}$ were evaluated in 292 USDA spinach germplasm accessions (Additional file 1: Table S1). The phenotypic data of the nine among the 14 elements in spinach germplasm accessions, including $\mathrm{Ca}, \mathrm{Cu}, \mathrm{Fe}, \mathrm{Mg}, \mathrm{Mn}, \mathrm{Mo}$, $\mathrm{Ni}, \mathrm{P}$, and $\mathrm{Zn}$, have been published partially in the USDA GRIN website at http://www.ars-grin.gov/cgibin/npgs/html/eval.pl?492376.

Accessions were grown in 1-1 black plastic pots filled with a 2:1 (vol: vol) mixture of commercially available soil (Metro-Mix 360; Scotts-Sierra Horticultural Products Co., Marysville, Ohio, USA) and vermiculite (Strong-Lite Medium Vermiculite; Sun Gro Horticulture Co, Seneca, Illinois, USA). There were six plants of each accession in a pot, with pots randomly distributed within a growth chamber (model PGW36; Controlled Environments Ltd., Winnipeg, Manitoba, Canada). Plants were grown on a $12 \mathrm{~h}$. photoperiod of $300 \mu \mathrm{mol} \mathrm{m} \mathrm{m}^{-2} \mathrm{~s}^{-1}$ photosynthetically active radiation (incandescent and fluorescent lamps) with a $20 \pm 0.5{ }^{\circ} \mathrm{C} / 15 \pm 0.5{ }^{\circ} \mathrm{C}$ day/ night temperature regime. Relative humidity was maintained at $50 \% \pm 5 \%$. Pots were initially irrigated with deionized water, and after emergence, plants were subirrigated daily with a nutrient solution containing the concentrations of mineral salts: $1.2 \mathrm{mM} \mathrm{KNO} 3,0.8 \mathrm{mM}$ $\mathrm{Ca}\left(\mathrm{NO}_{3}\right)_{2}, 0.8 \mathrm{mM} \mathrm{NH} \mathrm{NO}_{3}, 0.2 \mathrm{mM} \mathrm{MgSO}_{4}, 0.3 \mathrm{mM}$ $\mathrm{KH}_{2} \mathrm{PO}_{4}, 25 \mu \mathrm{M} \mathrm{CaCl}, 25 \mu \mathrm{M} \mathrm{H}_{3} \mathrm{BO}_{3}, 2 \mu \mathrm{m} \mathrm{MnSO}_{4}$, $2 \mu \mathrm{M} \mathrm{ZnSO}_{4}, 0.5 \mu \mathrm{M} \mathrm{CuSO}_{4}, 0.5 \mu \mathrm{M} \mathrm{H}_{2} \mathrm{MoO}_{4}, 0.1 \mu \mathrm{M}$ 
$\mathrm{NiSO}_{4}$, and $10 \mu \mathrm{M} \mathrm{Fe}(\mathrm{W})-\mathrm{N}, \mathrm{N}^{\prime}$-ethylenebis[2-(2-hydroxyphenyl)-glycine] (Sprint 138; Becker-Underwood, Inc., Ames, Iowa, USA).

Plants were harvested at 4-5 weeks after planting when they had 5-6 fully expanded leaves. Harvested material included both mature and immature leaves (leaf blades and petioles) from the six plants of each accession. Soil contamination of the samples was minimized by cutting plants $0.5 \mathrm{~cm}$ above the soil surface. Leaves were dried in paper bags at $65-70{ }^{\circ} \mathrm{C}$ for a minimum of $48 \mathrm{~h}$, and after cooling the pooled leaves from the 6 plants were ground to a uniform powder using a coffee grinder with stainless steel blades (model IDS 55; $\mathrm{Mr}$. Coffee, Boca Raton, Florida, USA). Two 0.25 g (dry weight) subsamples of each accession were wet digested in borosilicate glass tubes using ultra-pure nitric and perchloric acids, as previously described [55]. Digestages were resuspended in ultra-pure nitric acid and analyzed for concentrations of $\mathrm{B}, \mathrm{Ca}, \mathrm{Co}, \mathrm{Cu}, \mathrm{Fe}, \mathrm{K}, \mathrm{Mg}, \mathrm{Mn}, \mathrm{Mo}$, $\mathrm{Na}, \mathrm{Ni}, \mathrm{P}, \mathrm{S}$, and $\mathrm{Zn}$ using inductively coupled plasma optical emission spectrometry (CIROS ICP Model FCE12; Spectro, Kleve, Germany). Tomato leaf standards (SRM 1573A; National Institute of Standards and Technology, Gaithersburg, Maryland, USA) were digested and analyzed as quality control along with each run of 50 spinach samples to verify the reliability of the procedures and analytical measurements. Results are reported on a dry weight basis as the average of the two subsamples in ppm (parts per million; equivalent to micrograms per gram).

\section{DNA extraction, GBS, and SNP discovery}

Genomic DNA was extracted from freeze-dried fresh leaves of spinach plants using the CTAB (hexadecyltrimethyl ammonium bromide) method [56]. DNA sequencing was done by next generation sequencing technologies using GBS $[18,20]$ and GBS was conducted by HiSeq 2000 in Beijing Genome Institute (BGI). SOAP family software (http://soap.genomics.org.cn/) was used for sequence assembly, mapping and SNP discovery of GBS data. The GBS data averaged $3.26 \mathrm{M}$ short-read and 283.74 Mbp data-points for each spinach sample. The short reads of the GBS data were aligned to spinach genome reference AYZV02 (http://www.ncbi.nlm.nih. gov/Traces/wgs/?val=AYZV02) by using SOAPaligner/ soap2 (http://soap.genomics.org.cn/), while SOAPsnp v. 1.05 was used for SNP calling [57, 58]. Approximately a half million SNPs were discovered from the original GBS data from BGI among the 292 spinach germplasm accessions. The spinach accessions and SNPs were filtered before conducting genetic diversity and association analyses. If an accession had greater than $35 \%$ missing SNP data, the accession was removed from the panel. The SNP data were filtered by setting the parameters of minor allele frequency (MLF) $>2 \%$, missing data $<20 \%$, and heterozygous genotype $<10 \%$. After filtering, 2402 SNPs among 292 spinach accessions were used for genetic diversity and association analysis.

\section{Phenotypic data analysis}

Phenotypic data of the 14 mineral elements in spinach were analyzed using Microsoft Excel 2016 for the average, range, standard deviation, and coefficient of variation $(\mathrm{CV})$ and the distributions of the 14 mineral elements were drawn using QGene [35]. The correlation coefficients of the 14 mineral elements were calculated using JMP Genomics 7 software (SAS Institute, Cary, NC, USA). In JMP Genomics 7, the dendrogram construction was done using multivariate methods to do hierarchical clustering. After being clustered, the multivariate principal component analysis (PCA) was used to create biplot on covariance.

\section{Genetic diversity and population structure analysis}

The model-based program STRUCTURE 2 [33] was used to infer population structure. In order to identify the number of populations (K) capturing the major population structure in the tested spinach association panel, the burn-in period was set at 50,000 with the Markov Chain Monte Carlo iterations and the run length was set at 10,000 in an admixture model and correlated allele frequencies independent for each run [59]. Ten runs were performed for each simulated value of $\mathrm{K}$, ranging from 1 to 10 . The delta $\mathrm{K}$ was calculated using the formula provided by Evanno et al. (2005) [60]. The optimal $\mathrm{K}$ was determined with Structure Harvester [61]. After the optimal $\mathrm{K}$ was determined, a Q-matrix was generated; this was used in Tassel 5 for association analysis of mineral elements. Each spinach accession was also assigned to a cluster (Q) based on a probability for that accession in a cluster, using a cut-off probability of 0.50 . Based on the optimal K, a Bar plot with 'Sort by Q' was obtained to visualize the population structure of the spinach association panel.

Genetic diversity was also assessed and the phylogeny trees were drawn using MEGA 6 [34] based on the Maximum Likelihood tree method with the following parameters [17]. Test of Phylogeny: Bootstrap Method, No. of Bootstrap Replications: 500, Model/Method: General Time Reversible model, Rates among Sites: Gamma distributed with Invariant sites $(G+I)$, Number of Discrete Gamma Categories: 5, Gaps/Missing Data Treatment: Use all sites, ML Heuristic Method: Subtree-PruningRegrafting-Extensive (SPR level 5), Initial Tree for ML: Make initial tree automatically (Neighbor Joining), and Branch Swap Filter: Moderate. During the drawing of the phylogeny trees, the population structure and the cluster information were imported to MEGA 6 for 
combined analysis of genetic diversity. For sub-tree of each Q (cluster), the shape of 'Node/Subtree Marker' and the 'Branch Line' was drawn with the same color as in the figure of the Bar plot of the population clusters from the STRUCTURE analysis.

\section{Association analysis}

Association analysis was conducted with the single marker regression (SMR) without structure and kinship, the general linear model (GLM), and the mixed linear model (MLM) methods as described in TASSEL 5 [62] (http://www.maizegenetics.net/tassel) and the analysis was also performed with compressed mixed linear model (cMLM) [63] and enriched compressed mixed linear model (EcMLM) [64] implemented in the GAPIT $R$ package [65]. The QGene 4.3.10 was also used to conduct SMR for all SNPs [35], although QGene was developed for QTL mapping, it can also be used in association analysis through SMR. The effect of SNP markers were also conducted by T-test using JMP Genomics and Microsoft Excel 2016.

\section{Additional files}

Additional file 1: Table S1. Spinach PI accession number, name, origin/country, cluster assigned in this study, taxon name, and 14 mineral element concentrations in 292 germplasm accessions. Table S2. Spinach PI accession number, taxon name, origin country, cluster assigned in this study, mineral element, mineral ID ranked in top three, and 14 mineral element concentrations in 292 germplasm accessions. (XLSX 105 kb)

Additional file 2: Figure S1. The ring phylogenetic tree combining structure populations (Q1 to Q4) from STRUCTURE 2 and the Maximum Likelihood (ML) method from MEGA 6. The spinach accession number, the accession original country, and the structure population (cluster) were merged together into one taxon name as each spinach accession ID in the combined tree drawn by MEGA 6. The colored shape and branch of each cluster matched the structure population (red round shape for Q1, green triangle for Q2, blue triangle for Q3, yellow diamond for Q4, and the black square with the black branch for the admixture in 292 USDA GRIN spinach germplasm accessions. (XLSX 149 kb)

\section{Abbreviations}

B: Boron; Ca: Calcium; CMLM: Compressed mixed linear model using Gapit; Co: Cobalt; Cu: Copper; EcMLM: Enriched compressed mixed linear model using Gapit; Fe: Iron; GBS: Genotyping by sequencing; GLM: General linear model; GWAS: genome-wide association study; K: Potassium; MAS: Markerassisted selection; Mg: Magnesium; MLF: Minor allele frequency; MLM: Mixed linear model; Mn: Manganese; Mo: Molybdenum; Na: Sodium; Ni: Nickel; P: Phosphorus; S: Sulfur; SMR: Single marker regression; SNP: Single nucleotide polymorphism; Zn: Zinc

\section{Acknowledgements}

Not applicable.

\section{Funding}

(1) by USDA-ARS GRIN GERMPLASM EVALUATION PROPOSAL for National Plant Germplasm System (NPGS) by Crop Germplasm Committee (CGC) with Project Number: 58-5030-6-076 for proving spinach material collection and DNA extraction and sequencing; (2) USDA Specialty Crop Multistate Program (SCMP) for DAN extraction and sequencing; and (3) by the USDA National Institute of Food and Agriculture Hatch project accession number 1002423 for providing the project director and technician salary.

\section{Availability of data and materials}

All raw data for this article are provided in the Additional files 1 and 2 .

\section{Authors' contributions}

$J Q, A S, B M, M G, Y W, W R, G B, L D$, and WY carried out phenotyping and genotyping. AS and JQ analyzed the data. JQ and AS composed the draft of the manuscript. AS and MG directed and managed this research. BM and MG reviewed and edited the manuscript. All authors have read, made corrections and approved the final manuscript.

\section{Ethics approval and consent to participate}

All data and materials are not related to human and animals. All research materials of spinach germplasm accessions are obtained from USDA GRIN. This research is not related to any plant specimens to be deposited as vouchers or any other association for this section.

\section{Consent for publication}

Not applicable.

\section{Competing interests}

The authors declare that they have no competing interests.

\section{Publisher's Note}

Springer Nature remains neutral with regard to jurisdictional claims in published maps and institutional affiliations.

\section{Author details}

${ }^{1}$ Department of Horticulture, University of Arkansas, Fayetteville, AR 72701, USA. ${ }^{2}$ Crop Improvement and Protection Research Unit, USDA-ARS, Salinas, CA 93905, USA. ${ }^{3}$ USDA-ARS Red River Valley Agricultural Research Center, Fargo, ND 58102, USA.

Received: 6 July 2017 Accepted: 13 November 2017

Published online: 04 December 2017

\section{References}

1. Correll J, Bluhm B, Feng C, Lamour K, Du Toit L, Koike S. Spinach: better management of downy mildew and white rust through genomics. Eur J Plant Pathol. 2011;129(2):193-205

2. NASS U: NASS-National Agricultural Statistics Service. URL http://www nass usda gov/(accessed 27 august 2015) Varunsatian, S, Watanabe, K, Hayakawa, S, Nakamura 2015.

3. Decoteau DR: Vegetable crops: Pearson College div; 2000

4. Morelock TE, Correll JC. Spinach. Vegetables I. 2008:189-218.

5. Higdon J: An evidence-based approach to vitamins and minerals health benefits and intake recommendations: Thieme medical publishers, Inc.; 2003.

6. Prashanth L, Kattapagari KK, Chitturi RT, Baddam VRR, Prasad LK. A review on role of essential trace elements in health and disease. Journal of Dr NTR University of Health Sciences. 2015;4(2):75.

7. Berdanier CD, Dwyer JT, Heber D: Handbook of nutrition and food: CRC press; 2013.

8. Berdanier CD, Dwyer JT, Heber D: Handbook of nutrition and food: CRC press; 2016

9. Randhawa MA, Khan AA, Javed MS, Sajid MW. Chapter 18-green leafy vegetables: a health promoting source. Handbook of Fertility Academic Press, San Diego, CA. 2015:205-20.

10. Moose SP, Mumm RH. Molecular plant breeding as the foundation for $21 \mathrm{st}$ century crop improvement. Plant Physiol. 2008;147(3):969-77.

11. Collard B, Jahufer $M$, Brouwer J, Pang E. An introduction to markers, quantitative trait loci (QTL) mapping and marker-assisted selection for crop improvement: the basic concepts. Euphytica. 2005;142(1-2):169-96.

12. Collard BC, Mackill DJ. Marker-assisted selection: an approach for precision plant breeding in the twenty-first century. Philosophical Transactions of the Royal Society B: Biological Sciences. 2008;363(1491):557-72.

13. $\mathrm{Xu}$ Y, Crouch JH. Marker-assisted selection in plant breeding: from publications to practice. Crop Sci. 2008;48(2):391-407.

14. Lehne B, Lewis CM, Schlitt T. From SNPs to genes: disease association at the gene level. PLoS One. 2011;6(6):e20133. 
15. Taranto F, D'Agostino N, Greco B, Cardi T, Tripodi P. Genome-wide SNP discovery and population structure analysis in pepper (Capsicum Annuum) using genotyping by sequencing. BMC Genomics. 2016;17(1):943.

16. Li P, Guo M, Wang C, Liu X, Zou Q. An overview of SNP interactions in genome-wide association studies. Briefings in Functional Genomics. 2015; 14(2):143-55.

17. Shi A, Buckley B, Mou B, Motes D, Morris JB, Ma J, Xiong H, Qin J, Yang W, Chitwood J. Association analysis of cowpea bacterial blight resistance in USDA cowpea germplasm. Euphytica. 2016;208(1):143-55.

18. Elshire RJ, Glaubitz JC, Sun Q, Poland JA, Kawamoto K, Buckler ES, Mitchell SE. A robust, simple genotyping-by-sequencing (GBS) approach for high diversity species. PLoS One. 2011;6(5):e19379.

19. Davey JW, Hohenlohe PA, Etter PD, Boone JQ, Catchen JM, Blaxter ML. Genome-wide genetic marker discovery and genotyping using nextgeneration sequencing. Nat Rev Genet. 2011;12(7):499-510.

20. Sonah $H$, Bastien $M$, lquira $E$, Tardivel A, Légaré $G$, Boyle B, Normandeau É, Laroche J, Larose S, Jean M. An improved genotyping by sequencing (GBS) approach offering increased versatility and efficiency of SNP discovery and genotyping. PLoS One. 2013;8(1):e54603.

21. He J, Zhao X, Laroche A, Lu Z-X, Liu H, Li Z. Genotyping-by-sequencing (GBS), an ultimate marker-assisted selection (MAS) tool to accelerate plant breeding. Front Plant Sci. 2014;5:484.

22. Poland JA, Rife TW. Genotyping-by-sequencing for plant breeding and genetics. The Plant Genome. 2012;5(3):92-102.

23. Narum SR, Buerkle CA, Davey JW, Miller MR, Hohenlohe PA. Genotyping-bysequencing in ecological and conservation genomics. Mol Ecol. 2013;22(11): 2841-7.

24. Van Deynze A. A de novo draft assembly of spinach using Pacific biosciences technology. In. 2014:10-5

25. Van Deynze A, Ashrafi H, Hickey L, Peluso P, Rank D, Chin J, Rapicavoli N Drake J, Garvin T, Schatz M. Using spinach to compare technologies for whole genome assemblies. In. 2015:10-4.

26. Dohm JC, Minoche AE, Holtgräwe D, Capella-Gutiérrez S, Zakrzewski F, Tafer H, Rupp O, Sörensen TR, Stracke R, Reinhardt R. The genome of the recently domesticated crop plant sugar beet (Beta Vulgaris). Nature. 2014;505(7484): 546-9.

27. Minoche AE, Dohm JC, Schneider J, Holtgräwe D, Viehöver P, Montfort M, Sörensen TR, Weisshaar B, Himmelbauer H. Exploiting single-molecule transcript sequencing for eukaryotic gene prediction. Genome Biol. 2015; 16(1):184.

28. Shi A, Mou B, Correll JC. Association analysis for oxalate concentration in spinach. Euphytica. 2016;212(1):17-28.

29. Shi A, Mou B. Genetic diversity and association analysis of leafminer (Liriomyza Langei) resistance in spinach (Spinacia Oleracea). Genome. 2016; 59(8):581-8.

30. Shi A, Mou B, Correll J, Motes D, Weng Y, Qin J, Yang W: SNP association analysis of resistance to Verticillium wilt ('Verticillium dahliae'Kleb.) in spinach. Australian Journal of Crop Science 2016, 10(8):1188.

31. Shi A, Mou B, Correll J, Koike ST, Motes D, Qin J, Weng Y, Yang W. Association analysis and identification of SNP markers for Stemphylium leaf spot (Stemphylium botryosum f. sp. spinacia) resistance in spinach (Spinacia oleracea). American Journal of Plant Sciences. 2016;7(12):1600.

32. Ma J, Shi A, Mou B, Evans M, Clark JR, Motes D, Correll JC, Xiong H, Qin J, Chitwood J. Association mapping of leaf traits in spinach (Spinacia Oleracea L.). Plant Breed. 2016;135(3):399-404.

33. Pritchard JK, Stephens M, Donnelly P. Inference of population structure using multilocus genotype data. Genetics. 2000;155(2):945-59.

34. Tamura K, Stecher G, Peterson D, Filipski A, Kumar S. MEGA6: molecular evolutionary genetics analysis version 6.0. Mol Biol Evol. 2013;30(12):2725-9.

35. Joehanes R, Nelson JC. QGene 4.0, an extensible java QTL-analysis platform. Bioinformatics. 2008;24(23):2788-9.

36. Ma Y, Coyne CJ, Grusak MA, Mazourek M, Cheng P, Main D, McGee RJ. Genome-wide SNP identification, linkage map construction and QTL mapping for seed mineral concentrations and contents in pea (Pisum sativum L.). BMC plant biology, 2017. 17(1):43.

37. Anuradha K, Agarwal S, Rao Y, Rao K, Viraktamath B, Sarla N. Mapping QTLs and candidate genes for iron and zinc concentrations in unpolished rice of Madhukar× Swarna RILs. Gene. 2012;508(2):233-40.

38. Garcia-Oliveira AL, Tan L, Fu Y, Sun C. Genetic identification of quantitative trait loci for contents of mineral nutrients in rice grain. J Integr Plant Biol. 2009;51(1):84-92.
39. Stangoulis JCR, Huynh B-L, Welch RM, Choi E-Y, Graham RD. Quantitative trait loci for phytate in rice grain and their relationship with grain micronutrient content. Euphytica. 2007;154(3):289-94.

40. Huang Y, Sun C, Min J, Chen Y, Tong C, Bao J. Association mapping of quantitative trait loci for mineral element contents in whole grain Rice (Oryza Sativa L.). J Agric Food Chem. 2015;63(50):10885-92.

41. Norton GJ, Deacon CM, Xiong L, Huang S, Meharg AA, Price AH. Genetic mapping of the rice ionome in leaves and grain: identification of QTLs for 17 elements including arsenic, cadmium, iron and selenium. Plant Soil. 2010; 329(1-2):139-53.

42. Du J, Zeng D, Wang B, Qian Q, Zheng S, Ling H-Q. Environmental effects on mineral accumulation in rice grains and identification of ecological specific QTLs. Environ Geochem Health. 2013:35(2):161-70.

43. Sautter C, Poletti S, Zhang P, Gruissem W. Biofortification of essential nutritional compounds and trace elements in rice and cassava. Proc Nutr Soc. 2006;65(02):153-9.

44. Jiménez-Aguilar DM, Grusak MA. Evaluation of minerals, phytochemical compounds and antioxidant activity of Mexican, central American, and African green leafy vegetables. Plant Foods Hum Nutr. 2015;70(4):357-64.

45. Jiménez-Aguilar DM, Grusak MA. Minerals, vitamin C, phenolics, flavonoids and antioxidant activity of Amaranthus leafy vegetables. J Food Compos Anal. 2017;

46. Lin S-w. A comparative study of the determination of phosphorus by electrothermal atomic absorption spectrometry and solution spectrophotometry. Anal Chim Acta. 1984;158:199-206.

47. Stephen SC, Littlejohn D, Ottaway JM. Evaluation of a slurry technique for the determination of lead in spinach by electrothermal atomic-absorption spectrometry. Analyst. 1985;110(9):1147-51.

48. Bhattacharjee S, Dasgupta P, Paul AR, Ghosal S, Padhi KK, Pandey LP. Mineral element composition of spinach. J Sci Food Agric. 1998;77(4):456-8.

49. Alegría A, Barbera R, Farré R. Atomic-absorption spectrophotometric determination of nickel in foods. Journal of Micronutrient Analysis. 1988:4(3): 229-39.

50. Yan D, Schwedt G. Simultaneous ion chromatography of inorganic anions together with some organic anions and alkaline earth metal cations using chelating agents as eluents. J Chromatogr A. 1990;516(2):383-93.

51. Mittal R, Allawadhi KL, Sood BS, Singh N, Kumar A, Kumar P. Determination of potassium and calcium in vegetables by $\mathrm{x}$-ray fluorescence spectrometry. X-Ray Spectrom. 1993;22(6):413-7.

52. Rahmatollah R, Mahbobeh R. Mineral contents of some plants used in Iran. Pharm Res. 2010;2(4):267.

53. Saris N-EL, Mervaala E, Karppanen H, Khawaja JA, Lewenstam A. Magnesium: an update on physiological, clinical and analytical aspects. Clin Chim Acta. 2000:294(1):1-26.

54. Brody T. Protein. Brody T Nutritional biochemistry. 1994;2

55. Sankaran RP, Grusak MA. Whole shoot mineral partitioning and accumulation in pea (Pisum Sativum). Front Plant Sci. 2014;5(April):1-8.

56. Kisha T, Sneller C, Diers B. Relationship between genetic distance among parents and genetic variance in populations of soybean. Crop Sci. 1997; 37(4):1317-25.

57. Li H. A statistical framework for SNP calling, mutation discovery, association mapping and population genetical parameter estimation from sequencing data. Bioinformatics. 2011:27(21):2987-93.

58. Li H, Handsaker B, Wysoker A, Fennell T, Ruan J, Homer N, Marth G, Abecasis G, Durbin R. The sequence alignment/map format and SAMtools. Bioinformatics. 2009;25(16):2078-9.

59. Lv J, Qi J, Shi Q, Shen D, Zhang S, Shao G, Li H, Sun Z, Weng Y, Shang Y: Genetic diversity and population structure of cucumber (Cucumis sativus L.). PLoS One 2012, 7(10):e46919.

60. Evanno G, Regnaut S, Goudet J. Detecting the number of clusters of individuals using the software STRUCTURE: a simulation study. Mol Ecol. 2005;14(8):2611-20.

61. Earl DA. STRUCTURE HARVESTER: a website and program for visualizing STRUCTURE output and implementing the Evanno method. Conserv Genet Resour. 2012;4(2):359-61.

62. Bradbury PJ, Zhang Z, Kroon DE, Casstevens TM, Ramdoss Y, Buckler ES. TASSEL: software for association mapping of complex traits in diverse samples. Bioinformatics. 2007:23(19):2633-5.

63. Zhang Z, Ersoz E, Lai C-Q, Todhunter RJ, Tiwari HK, Gore MA, Bradbury PJ, Yu J, Arnett DK, Ordovas JM. Mixed linear model approach adapted for genome-wide association studies. Nat Genet. 2010;42(4):355-60. 
64. Huang X, Wei X, Sang T, Zhao Q, Feng Q, Zhao Y, Li C, Zhu C, Lu T, Zhang Z. Genome-wide association studies of 14 agronomic traits in rice landraces, Nat Genet. 2010;42(11):961-7.

65. Lipka AE, Tian F, Wang Q, Peiffer J, Li M, Bradbury PJ, Gore MA, Buckler ES, Zhang Z. GAPIT: genome association and prediction integrated tool. Bioinformatics. 2012;28(18):2397-9.

Submit your next manuscript to BioMed Central and we will help you at every step:

- We accept pre-submission inquiries

- Our selector tool helps you to find the most relevant journal

- We provide round the clock customer support

- Convenient online submission

- Thorough peer review

- Inclusion in PubMed and all major indexing services

- Maximum visibility for your research

Submit your manuscript at www.biomedcentral.com/submit 